\title{
Process, revived
}

\author{
Ambitious emission reduction targets from governments and businesses revive hope in a political solution to \\ climate change, but need to be examined rigorously.
}

$\Lambda$ fter the 2009 United Nations Climate Change Conference in Copenhagen failed to produce a pathway to any kind of binding agreement on global emission reductions, it appeared the geopolitics of climate change had become too complex to produce an effective solution. It seemed that every significant voting bloc from BASIC (Brazil, South Africa, India and China) to OPEC (Organization of the Petroleum Exporting Countries) to the European Union was at loggerheads with each other and with the highest emitter at the time, the USA. In the days that followed, a sort of despondence set in within the climate movement that appears to have lasted the decade.

The Paris Agreement in 2015 to limit global warming to well below $2{ }^{\circ} \mathrm{C}$ helped allay some of the scepticism born of the failure of the Copenhagen talks. However, the hope was short lived: the commitments submitted by the signatory nations did not come close to meeting the $2{ }^{\circ} \mathrm{C}$ goal ${ }^{1}$. To make matters worse, President Trump withdrew the USA from the Agreement, potentially discouraging many other big emitters from unilaterally following through with their commitments as well. It appeared as though the Paris Agreement was a mirage and not a milestone.

Recent developments, however, provide cause for cautious optimism. Within the first hundred days of inauguration, the Biden administration rejoined the Paris Agreement and called for a Leaders Summit on Climate, inviting the 17 biggest economies and greenhouse gas emitters in the world ${ }^{2}$. At the summit, China reiterated its commitment to peak carbon dioxide emissions before 2030 and to achieve carbon neutrality before $2060^{3}$. Surprisingly, the USA committed to halving its emissions by 2030 (against a 2005 baseline $)^{4}$. Brazil vowed carbon neutrality by 2050 , Japan pledged $46 \%$ emission reductions by 2030 against a 2013 baseline and Canada set a target of $40 \%$ reductions by 2030 against a 2005 baseline.

This ambitiousness by some of the world's largest emitters appears to have set the tone for aggressive climate policy in the coming years. Ahead of the G7 meeting on climate change in the UK in June, member countries agreed to stop all new financing for coal energy projects. At the end of May, President Biden issued an executive order directing the National Economic Council and National
Climate Advisor to develop a strategy for climate-related financial disclosures.

Business and industry surprisingly appear to be taking the lead and spurring government action on climate. Net-zero commitments from cities and businesses have nearly doubled in less than a year ${ }^{5}$. While many of these targets are longer term and won't be achieved till 2050, there appears to be a concerted effort to at least demonstrate ambitiousness.

Despite this ambition, there continues to be cause for scepticism. At the national level, stated emission reduction goals in the USA and many other countries have yet to be translated into actionable law and policy and still miss the $1.5^{\circ} \mathrm{C}$ target. At the level of business and industry, there is increasing evidence that lofty goals do not always translate into effective action on the ground. For instance, one study found that utilities maintained or increased their share of fossil fuel generation even while committing to ambitious emission reductions ${ }^{6}$.

In a Comment in this issue, Ryan Hanna and David Victor wonder if the jump on the bandwagon of net-zero pledges is reflective of a new wave of greenwashing. One of the main limitations of emission reduction commitments is that rigorous systems don't exist to implement, examine and monitor many of the pledged targets. The scientific community has a critical role to play in this new world of ambitious goals and weak monitoring mechanisms.

First, key terms, ambitions and scenarios all need to be rigorously defined. For net-zero claims, the boundaries of energy systems being transitioned need to be spelled out with clarity, specificity and transparency. Research that defines these boundaries for different kinds of systems, enterprises and national and non-national governments can be useful towards assessing the on-the-ground emission reduction potential of many of the goals. Scientific standardization that then allows for comparability across goals from different institutions would also be important. This kind of research would allow for development of rigorous mechanisms to evaluate and monitor the impact of policy. We would better understand what 'net-zero' means in terms of actual emissions on the ground. We would have clear accounting of emissions outsourced by countries aiming to achieve carbon neutrality.
Second, scenarios should start engaging more concretely with political and empirical realities. While it is useful to develop net-zero or other high-ambition scenarios for governments as well as for industries, the drastic change in trajectory such scenarios may require - for instance in trends of energy intensity of certain industries or society at large - need to be acknowledged. The political realities that may continue to hinder the realization of scenarios need to be acknowledged. The technical breakthroughs that are needed to make the scenario a reality need to be acknowledged. The optimistic scenarios should always be contrasted against baseline scenarios that do not imagine drastic change in energy intensity trends or reversal in political consensus.

Scientists have been demonstrating the technoeconomic feasibility of the renewable energy transition with scenarios for decades. These demonstrations have traditionally given us hope that there are solutions out there in the face of mounting climate catastrophe. Business and politics seem to have now taken it upon themselves to signal ambitious goals, leading the charge in terms of creating hope for a green energy future. While the scientific community might allow itself to savour the moment and dream a little, it must also continue to ensure highest standards of rigour in examining the veracity and viability of all targets, especially the most optimistic pledges.

Published online: 21 June 2021

https://doi.org/10.1038/s41560-021-00861-2

References

1. "Climate commitments not on track to meet Paris Agreement goals" as NDC synthesis report is published. UNFCCC https:// unfccc.int/news/climate-commitments-not-on-track-to-meetparis-agreement-goals-as-ndc-synthesis-report-is-published (2021).

2. Leaders Summit on Climate. US Department of State https://www. state.gov/leaders-summit-on-climate/ (2021).

3. Xi Jinping attends the Leaders Summit on Climate and delivers an important speech. Ministry of Foreign Affairs of the People's Republic of China https://www.fmprc.gov.cn/mfa_eng/ zxxx_662805/t1871057.shtml (2021).

4. Fact sheet: President Biden sets 2030 greenhouse gas pollution reduction target aimed at creating good-paying union jobs and securing U.S. leadership on clean energy technologies. The White House https://www.whitehouse.gov/briefing-room/ statements-releases/2021/04/22/fact-sheet-president-biden-sets2030-greenhouse-gas-pollution-reduction-target-aimed-atcreating-good-paying-union-jobs-and-securing-u-s-leadershipon-clean-energy-technologies/ (2021).

5. Commitments to net zero double in less than a year. UNFCCC https://unfccc.int/news/commitments-to-net-zero-doublein-less-than-a-year (2021).

6. Alova, G. Nat. Energy 5, 920-927 (2020). 